\title{
Epidemiological Study of Return to Work and Mortality in Lung Cancer Survivors
}

\author{
Zhe-Yu Yang ${ }^{1}$, Ching-Huang Lai ${ }^{2} \mathbb{C}$, Ching-Liang $\mathrm{Ho}^{3}$ and Chung-Ching Wang $1,4, *$ (1) \\ 1 Division of Family Medicine, Department of Family and Community Medicine, Tri-Service General Hospital, \\ National Defense Medical Center, Taipei 114, Taiwan; yang820731@gmail.com \\ 2 School of Public Health, National Defense Medical Center, Taipei 114, Taiwan; lgh@mail.ndmctsgh.edu.tw \\ 3 Division of Hematology/Oncology, Department of Medicine, Tri-Service General Hospital, School of \\ Medicine, National Defense Medical Center, Taipei 114, Taiwan; charileho22623@gmail.com \\ 4 Division of Occupational Medicine, Department of Family \& Community Medicine, Tri-Service General \\ Hospital, National Defense Medical Center, Taipei 114, Taiwan \\ * Correspondence: bigching@gmail.com; Tel.: +886-2-87923311
}

check for updates

Citation: Yang, Z.-Y.; Lai, C.-H.;

Ho, C.-L.; Wang, C.-C.

Epidemiological Study of Return to Work and Mortality in Lung Cancer Survivors. Int. J. Environ. Res. Public Health 2022, 19, 309. https://doi.org/ 10.3390/ijerph19010309

Academic Editors: Oliver Faust, U

Rajendra Acharya and Paul

B. Tchounwou

Received: 9 November 2021

Accepted: 26 December 2021

Published: 28 December 2021

Publisher's Note: MDPI stays neutral with regard to jurisdictional claims in published maps and institutional affiliations.

Copyright: (c) 2021 by the authors. Licensee MDPI, Basel, Switzerland. This article is an open access article distributed under the terms and conditions of the Creative Commons Attribution (CC BY) license (https:// creativecommons.org/licenses/by/ $4.0 /)$.

\begin{abstract}
Lung cancer is the second most common cancer and the leading cause of cancer-related deaths worldwide. Return to work (RTW) plays an important role for lung cancer survivors. Few studies focus solely on the relationship among possible variables and the RTW of lung cancer patients. The aim of our study was to examine sociodemographic, disease-related and work-related factors associated with RTW among lung cancer survivors in Taiwan. A total of 2206 employees who had been diagnosed with lung cancer at the Labor Insurance Database (LID), Taiwan Cancer Registry (TCR) and the National Health Insurance Research Database (NHIRD) during the period 2004-2015, were included in the study. We used the Cox proportional hazards model to investigate the associations between sociodemographic, disease-related and work-related factors on one hand and RTW on the other hand. The Kaplan-Meier method was used for analyzing the survival probability. Patients with an early cancer stage and those who underwent surgery had a higher likelihood of RTW. Factors including older age, male, higher monthly income and receipt of radiotherapy were inversely correlated with RTW. For lung cancer patients, RTW was a predictor of a lower risk of all-cause mortality in both the unadjusted and fully adjusted model. A better survival rate was found in stage III and IV lung cancer patients who had RTW. Sociodemographic and clinical-related variables had an impact on RTW among employees with lung cancer. RTW was correlated with a lower risk of all-cause mortality and better lung cancer survival. Our study showed the influence of RTW and independent confounding factors in lung cancer survivorship.
\end{abstract}

Keywords: lung cancer; return to work; survival outcome

\section{Introduction}

Lung cancer is the second most common cancer and the leading cause of cancerrelated deaths in both sexes worldwide [1]. A total of 235,760 estimated new cases of lung cancer and 131,880 deaths from lung cancer were reported in the US in 2021 [2]. Lung cancer accounted for 19\% of cancer deaths in Taiwan in 2017. Lung cancer mortality rates are high and overall 5-year survival rates are $21 \%$ [2]. Tobacco smoking, occupational exposures, air pollution and genetic predisposition are risk factors of lung cancer [3]. In Asia, exposure to indoor air pollution from cooking plays a crucial role in female lung cancer [4]. Traditional treatments for lung cancer included surgery, chemotherapy and radiotherapy [5]. In the past two decades, targeted therapies have been developed and approved as first-line therapies in lung cancer [6]. Immunotherapy had also been developed as a possible treatment option [7].

Mortality rates from lung cancer have been dropping due to lung cancer screening and novel treatment strategies $[8,9]$. However, lung cancer survivors still face many issues, in- 
cluding physical disability, psychological distress and social relationship problems [10,11]. Patients experienced pain, fatigue, weakness, shortness of breath and exercise intolerance [12]. Depression and anxiety were also present in patients with lung cancer $[13,14]$. The cost of cancer treatment and the loss of employment after a lung cancer diagnosis might cause economic problems [15]. Emerging studies have discussed the high financial burden that cancer patients face $[16,17]$. Moreover, a prior study reported that the unemployment rates of patients with lung cancer were two-fold higher than that of the general population [18]. Thus, the impact of lung cancer on RTW is worthy of attention.

Previous studies have investigated the correlation between the RTW of lung cancer survivors and variable factors $[19,20]$. However, prior research included limited samples of lung cancer survivors (<500 subjects). A paucity of studies investigated the relationship between RTW and survival rate for lung cancer patients. The objective of our retrospective cohort study was first, to explore the demographic, clinical and occupational variables correlated with RTW and second, to examine the association between RTW and survival rate among lung cancer survivors in Taiwan.

\section{Materials and Methods}

\subsection{Study Population and Database}

During the period 2004-2015, 2206 employees were newly diagnosed with lung cancer (ICD-O-3); information on these employees was collected from the Taiwan National Cancer Registry (TNCR) and the Taiwan Labor Insurance Database (LID) for this retrospective cohort study. Detailed descriptions are summarized in Figure 1. According to the International Classification of Diseases for Oncology-3rd edition (ICD-O-3), a primary diagnosis of lung cancer is coded. We utilized the unique encryption identity number to link these 2 databases in order to obtain sociodemographic information, such as age, employment information, employee's industry, monthly income and company size. Disease-related information, including primary cancer site, cancer stage and types of treatment, were also collected. The exclusion criteria of our study were (1) death before enrolled period; (2) patients who had lung cancer combined with other cancer or unknown timing of lung cancer diagnosis; (3) lung cancer patient who was unemployed at baseline; (4) lung cancer diagnosis after 2010. The study protocol was reviewed by the Institutional Review Board (IRB) of Tri-Service General Hospital (TSGH) (IRB No. 1-107-05-129).

\subsection{Sociodemographic and Disease-Related Information}

Sociodemographic data from the LID included age, monthly income, employment data, employee's industry and company size. In accordance with the International Classification of Diseases, Ninth Revision, Clinical Modification (ICD-9-CM) codes, clinical comorbidities were identified from National Health Insurance Research Database (NHIRD), including disorders of lipid metabolism, alcohol abuse, cerebrovascular diseases, chronic pulmonary diseases, peptic ulcer diseases, renal diseases, liver diseases and depression. Supplemental Table S1 lists the ICD-9-CM codes for clinical comorbidities. We also collected diseaserelated data, such as types of treatment and the pathological stage of lung cancer from TNCR and NHIRD.

\subsection{Outcome Assessment}

RTW was defined as employees who have still-insured labor insurance or first time reinsured labor insurance within 1 year of their lung cancer diagnosis. Non-RTW was defined as employees who exited labor insurance within 1 year of their lung cancer diagnosis and did not re-insure again. We selected an RTW period of 1-5 years after their first lung cancer diagnosis. We identified the information regarding RTW from employment data within LID. Every eligible participant was traced from their first-time primary diagnosis of lung cancer to the date of their death or the end of their follow-ups. We set the all-cause mortality (death from all causes) within the period 2004-2015 as the study endpoint. 


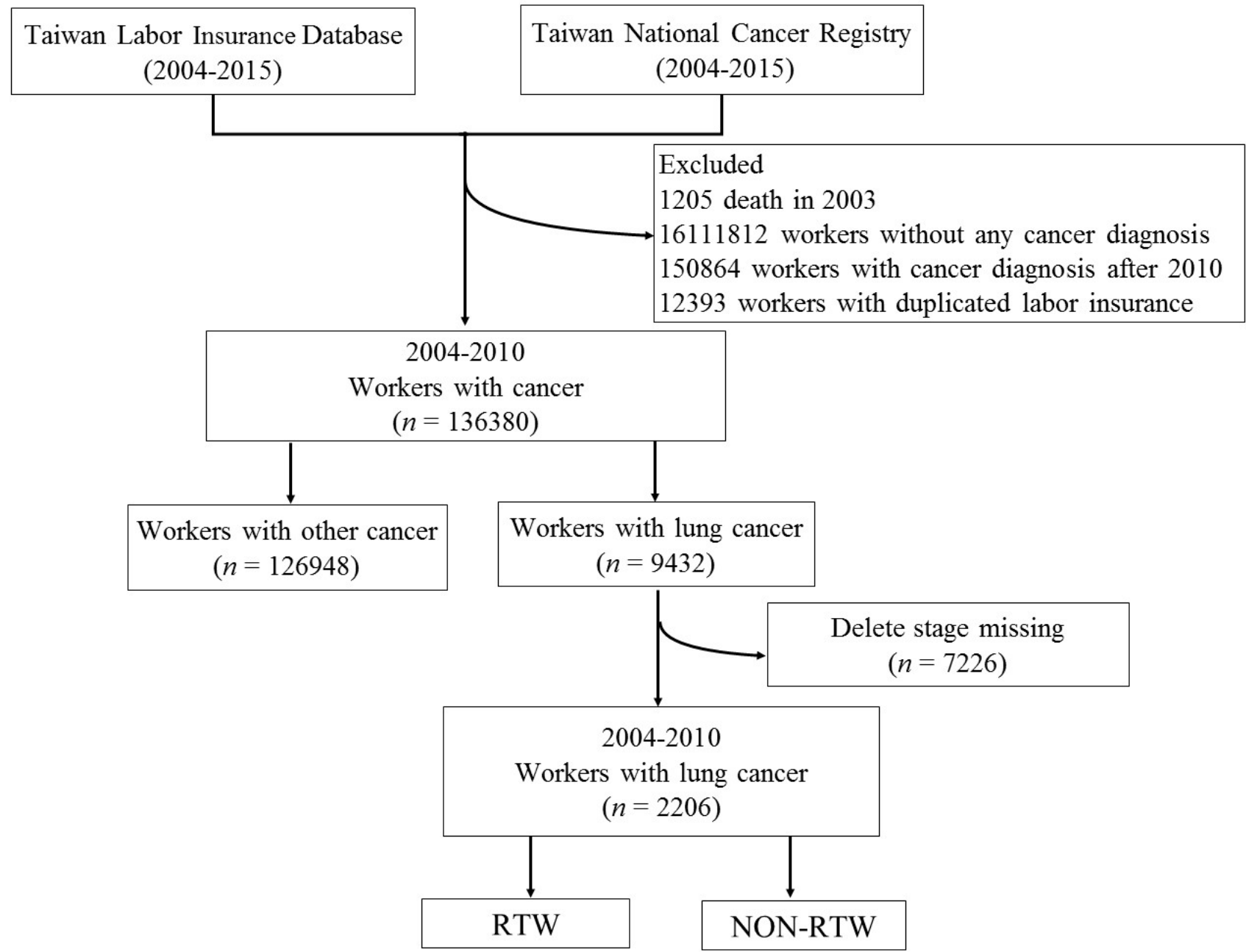

Figure 1. Flow chart of study population.

\subsection{Statistical Analysis}

PROC PHREG of the SAS statistical package (version 9.4, SAS Institute Inc., Cary, NC, USA) was utilized to perform our data analyses. Two-sided $p$ values $<0.05$ were considered to be statistically significant. RTW was determined from the data of their first primary diagnosis of lung cancer to the reemployment date within five years. Survival time was calculated from the data of their first primary diagnosis of lung cancer to the date of their death during the follow-up period (2004-2015). The results of statistical analyses are described as the means, standard deviations (SD) and percentages. Differences of categorical variables between subgroups were analyzed by using a chi-squared test. Continuous variables were compared by using an independent $t$-test.

Cox regression is a technique for evaluating the association between variables and specific events [21]. We used a multivariable Cox proportional hazard regression as a statistical model to assess (1) the impact of confounding factors on RTW and (2) the relationship between all-cause mortality and RTW among lung cancer patients. Covariates including age, gender, pathological stage of lung cancer, received treatment, monthly income, employee's industry and company size were adjusted. The HR (hazard ratio) represented the chance of RTW. Lastly, we used the Kaplan-Meier method to analyze the survival probability [22] and log-rank test to differentiate the survival curves between RTW and non-RTW groups. 


\section{Results}

\subsection{Characteristics of the Study Population}

The sociodemographic characteristics of the study population are shown in Table 1. The mean age of the participants was $53.5 \pm 8.2$ years. Of the 2206 patients, 1095 (49.6\%) workers were male and 1109 (50.2\%) workers had a monthly income range below USD 960. In this study, the early stage (stage 0 and I) of lung cancer were in the majority (48.4\%), followed by stage IV (20.3\%), stage III (19.6\%) and stage II (11.6\%). A total of 1805 (81.8\%) employees received surgical intervention, while less than half of the workers received chemotherapy $(39.4 \%)$ or radiotherapy $(15.5 \%)$. The employment rates of lung cancer survivors 2 and 5 years after their RTW were $60.3 \%$ and $41.1 \%$, respectively.

Table 1. Characteristics of the study population.

\begin{tabular}{|c|c|c|c|c|c|c|c|c|}
\hline \multirow[b]{2}{*}{ Characteristic } & \multicolumn{2}{|c|}{ Total } & \multicolumn{3}{|c|}{ RTW Group } & \multicolumn{3}{|c|}{ Non-RTW Group } \\
\hline & $\begin{array}{c}\text { Number of } \\
\text { Patient }\end{array}$ & $\%$ & $\begin{array}{c}\text { 2-Year } \\
\text { RTW } \\
n=1332\end{array}$ & $\begin{array}{c}\text { 5-Year } \\
\text { RTW } \\
n=908\end{array}$ & $p$ Value & $\begin{array}{c}\text { 2-Year } \\
\text { RTW } \\
n=874\end{array}$ & $\begin{array}{c}\text { 5-Year } \\
\text { RTW } \\
n=1298\end{array}$ & $p$ Value \\
\hline Age(year) ${ }^{a}$ & $\begin{array}{c}53.5 \pm 8.2 \\
(26-91)\end{array}$ & - & $\begin{array}{c}52.8 \pm 8 \\
(26-81)\end{array}$ & $\begin{array}{c}52.3 \pm 8 \\
(26-81)\end{array}$ & & $\begin{array}{c}54.6 \pm 8.4 \\
(26-91)\end{array}$ & $\begin{array}{c}54.4 \pm 8.2 \\
(26-91)\end{array}$ & \\
\hline $\begin{array}{c}\text { Gender } \\
\text { Male } \\
\text { Comorbidities }\end{array}$ & 1095 & 49.63 & 553 & 346 & 0.1059 & 542 & 749 & 0.0449 \\
\hline Lipoid metabolism & 289 & 13.1 & 188 & 120 & 0.5445 & 101 & 169 & 0.3106 \\
\hline Alcohol abuse & 20 & 0.9 & 10 & 6 & 0.804 & 10 & 14 & 0.886 \\
\hline Hypertension & 501 & 22.71 & 289 & 191 & 0.708 & 212 & 310 & 0.8417 \\
\hline Congestive heart failure & 34 & 1.54 & 22 & 10 & 0.2812 & 12 & 24 & 0.3942 \\
\hline Peripheral vascular disease & 23 & 1.04 & 12 & 10 & 0.6368 & 11 & 13 & 0.5741 \\
\hline Cerebrovascular disease & 60 & 2.71 & 30 & 18 & 0.665 & 30 & 42 & 0.8017 \\
\hline Chronic pulmonary disease & 396 & 17.95 & 215 & 144 & 0.8582 & 181 & 252 & 0.4589 \\
\hline Rheumatologic disease & 36 & 1.63 & 28 & 22 & 0.6138 & 8 & 14 & 0.7094 \\
\hline Peptic ulcer disease & 240 & 10.87 & 139 & 104 & 0.4467 & 101 & 136 & 0.4292 \\
\hline Mild liver disease & 206 & 9.33 & 117 & 78 & 0.8733 & 89 & 128 & 0.8063 \\
\hline Renal disease & 32 & 1.45 & 24 & 12 & 0.3749 & 8 & 20 & 0.2051 \\
\hline \multicolumn{9}{|l|}{ Comorbidity } \\
\hline 0 & 1097 & 49.72 & 676 & & & & & \\
\hline 1 & 578 & 26.2 & 348 & & & & & \\
\hline 2 & 322 & 14.59 & 189 & & & & & \\
\hline$\geq 3$ & 209 & 9.47 & 119 & & & & & \\
\hline \multicolumn{9}{|l|}{ Treatment } \\
\hline $\mathrm{OP}$ & 1805 & 81.82 & 1211 & 859 & 0.0012 & 594 & 946 & 0.0133 \\
\hline RTB & 343 & 15.54 & 141 & 62 & 0.0024 & 202 & 281 & 0.4212 \\
\hline $\mathrm{CH}$ & 870 & 39.43 & 477 & 272 & 0.0039 & 393 & 598 & 0.6121 \\
\hline Monthly income (USD) & & & & & 0.1728 & & & 0.312 \\
\hline$\leq \$ 960$ & 1109 & 50.27 & 715 & 519 & & 394 & 590 & \\
\hline$>\$ 960-\$ 1273$ & 395 & 17.9 & 270 & 182 & & 125 & 213 & \\
\hline$>\$ 1273$ & 702 & 31.82 & 347 & 207 & & 355 & 495 & \\
\hline Employee's industry & & & & & 0.9589 & & & 0.9977 \\
\hline Agriculture & 154 & 6.98 & 97 & 69 & & 57 & 85 & \\
\hline Manufacturing & 692 & 31.36 & 415 & 290 & & 277 & 402 & \\
\hline Electricity and Gas Supply & 14 & 0.63 & 8 & 4 & & 6 & 10 & \\
\hline Water Supply & 13 & 0.58 & 7 & 5 & & 6 & 8 & \\
\hline Construction & 232 & 10.51 & 129 & 95 & & 103 & 137 & \\
\hline Wholesale and Retail Trade & 254 & 11.51 & 152 & 90 & & 102 & 164 & \\
\hline Transportation and Storage & 168 & 7.61 & 99 & 54 & & 69 & 114 & \\
\hline Food Service & 74 & 3.35 & 46 & 30 & & 28 & 44 & \\
\hline
\end{tabular}


Table 1. Cont.

\begin{tabular}{|c|c|c|c|c|c|c|c|c|}
\hline \multirow[b]{2}{*}{ Characteristic } & \multicolumn{2}{|c|}{ Total } & \multicolumn{3}{|c|}{ RTW Group } & \multicolumn{3}{|c|}{ Non-RTW Group } \\
\hline & $\begin{array}{c}\text { Number of } \\
\text { Patient }\end{array}$ & $\%$ & $\begin{array}{c}\text { 2-Year } \\
\text { RTW } \\
n=1332\end{array}$ & $\begin{array}{c}\text { 5-Year } \\
\text { RTW } \\
n=908\end{array}$ & $p$ Value & $\begin{array}{c}\text { 2-Year } \\
\text { RTW } \\
n=874\end{array}$ & $\begin{array}{c}\text { 5-Year } \\
\text { RTW } \\
n=1298\end{array}$ & $p$ Value \\
\hline Information & 30 & 1.35 & 22 & 14 & & 8 & 16 & \\
\hline Financial & 82 & 3.71 & 50 & 36 & & 32 & 46 & \\
\hline Real Estate Activities & 29 & 1.31 & 18 & 6 & & 11 & 23 & \\
\hline Technical Activities & 63 & 2.85 & 32 & 23 & & 31 & 40 & \\
\hline Support Service Activities & 63 & 2.85 & 38 & 29 & & 25 & 34 & \\
\hline Public Administration & 40 & 1.81 & 18 & 15 & & 22 & 25 & \\
\hline Education & 36 & 1.63 & 21 & 14 & & 15 & 22 & \\
\hline Human Health & 67 & 3.03 & 47 & 40 & & 20 & 27 & \\
\hline Arts & 28 & 1.26 & 18 & 10 & & 10 & 18 & \\
\hline Other Service Activities & 167 & 7.57 & 115 & 84 & & 52 & 83 & \\
\hline Company size ${ }^{b}$ & & & & & 0.8169 & & & 0.6518 \\
\hline Company closed & 187 & 8.47 & 104 & 62 & & 83 & 125 & \\
\hline Small & 167 & 7.57 & 90 & 65 & & 77 & 102 & \\
\hline Medium & & & 260 & 183 & & 200 & 277 & \\
\hline Large & & & 878 & 598 & & 514 & 794 & \\
\hline Pathological stage & & & & & $<0.0001$ & & & 0.0586 \\
\hline $0 \& \mathrm{I}$ & 1068 & 48.41 & 776 & 611 & & 292 & 457 & \\
\hline II & 257 & 11.65 & 168 & 116 & & 89 & 141 & \\
\hline III & 433 & 19.62 & 252 & 126 & & 181 & 307 & \\
\hline IV & 448 & 20.3 & 136 & 55 & & 312 & 393 & \\
\hline
\end{tabular}

Abbreviation: $\mathrm{RTW}=$ return to work, $\mathrm{OP}=$ operation, $\mathrm{RTB}=$ radiotherapy, $\mathrm{CH}=$ chemotherapy. ${ }^{\text {a }}$ values are mean (standard deviation). ${ }^{\mathrm{b}}$ Company size: small (less than 5 people), medium (less than 200 people in manufacturing, construction, mining and quarrying; or less than 100 people in other industries), large (more than 200 people in manufacturing, construction, mining and quarrying; or more than 100 people in other industries).

\subsection{Univariate Analysis of Independent Factors Associated with RTW in Cox Proportional Hazards Models}

Figure 2 shows the independent factors associated with RTW using univariate Cox proportional hazards models. A lower likelihood of RTW was associated with older age, male and a monthly income above USD 1273. The patients who received chemotherapy or radiotherapy were less likely to RTW. These two HRs gradually declined during the follow-up period (chemotherapy: second year $\mathrm{HR}=0.84 ; 95 \% \mathrm{CI}=0.75-0.94$ to fifth year $\mathrm{HR}=0.64 ; 95 \% \mathrm{CI}=0.55-0.73$; radiotherapy: second year $\mathrm{HR}=0.63 ; 95 \% \mathrm{CI}=0.52-0.75$ to fifth year $\mathrm{HR}=0.39 ; 95 \% \mathrm{CI}=0.3-0.51$ ). A greater likelihood of RTW was associated with early stage cancer and receiving surgery.

\subsection{Multivariate Analysis of Independent Factors Associated with RTW in Cox Proportional Hazards Models}

An examination of the correlation of RTW and independent factors using multivariate Cox proportional hazards models suggested that the factors correlated with a lower likelihood of RTW were older age, male, a monthly income above USD 1273 and receiving radiotherapy (Figure 3). The patients who received surgery had a higher chance of RTW during the study period. Compared with the participants with stage IV, the participants with stage 0 , I, II or III had a higher chance of RTW.

\subsection{Survival Rates by RTW and Non-RTW}

The survival rates using the Kaplan-Meier curve stratified by RTW and non-RTW are listed in Figure 4 . The patients who had RTW had a better survival probability than those who had not RTW in all the cases of lung cancer $(p<0.001)$ and especially for patients with stage III and IV $(p<0.01)$. 


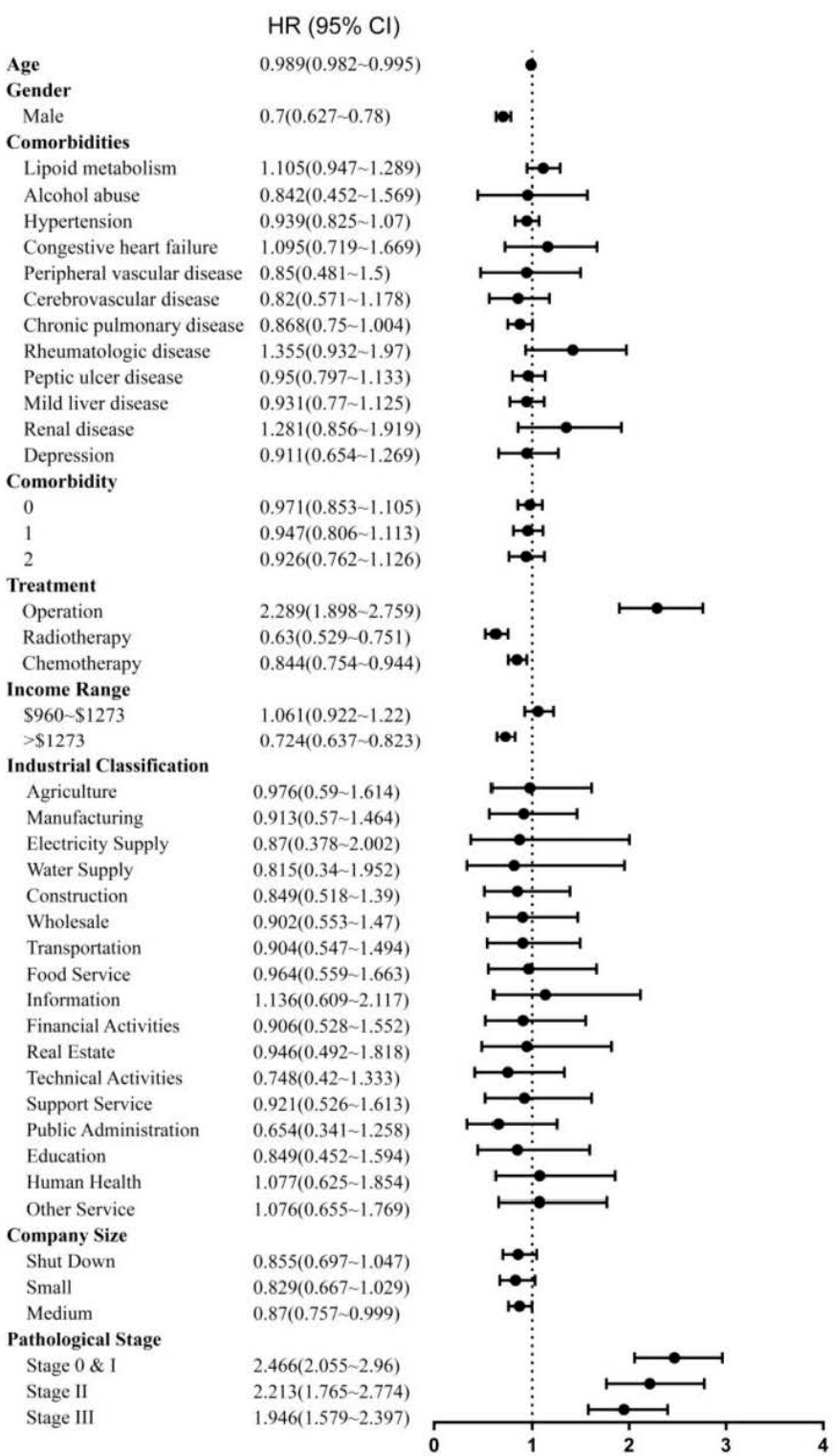

(A) 2-year RTW

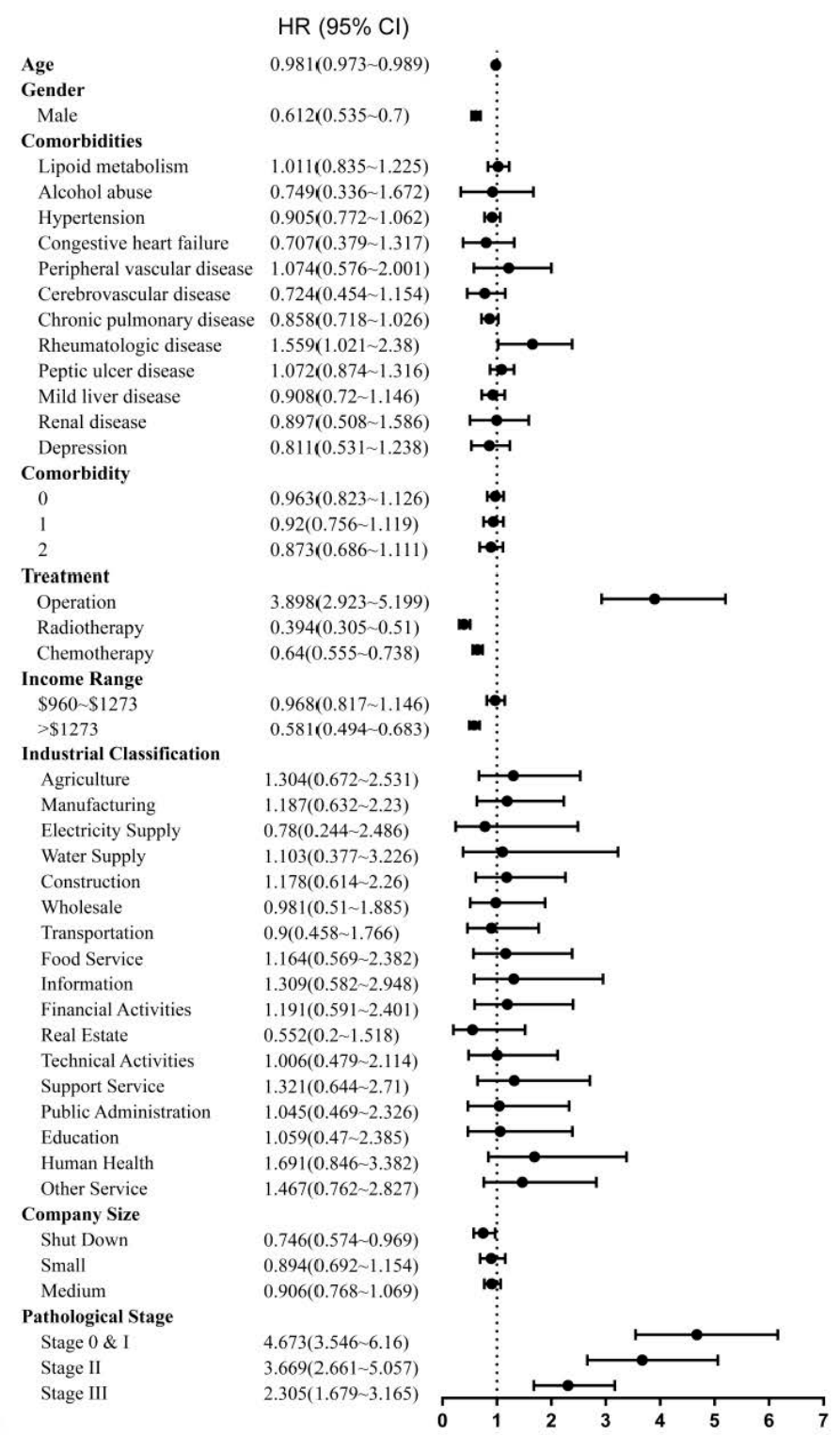

(B) 5-year RTW

Figure 2. Forest tree plot showing the HR obtained by univariate Cox proportional hazards model of return to work for lung cancer survivors in (A) 2-year RTW and (B) 5-year RTW. 


\begin{tabular}{ll} 
& \multicolumn{1}{c}{$\mathrm{HR}(95 \% \mathrm{Cl})$} \\
Age & $0.988(0.981 \sim 0.995)$ \\
Gender & \\
Male & $0.789(0.703 \sim 0.885)$ \\
Comorbidity & \\
0 & $1.049(0.856 \sim 1.287)$ \\
1 & $0.992(0.802 \sim 1.227)$ \\
2 & $1.042(0.827 \sim 1.313)$ \\
Treatment & \\
Operation & $1.587(1.272 \sim 1.98)$ \\
Radiotherapy & $0.806(0.667 \sim 0.975)$ \\
Chemotherapy & $1.088(0.96 \sim 1.234)$ \\
Income Range & \\
\$960-\$1273 & $1.09(0.944 \sim 1.26)$ \\
>\$1273 & $0.73(0.634 \sim 0.841)$ \\
Industrial Classification & \\
Agriculture & $1(0.603 \sim 1.658)$ \\
Manufacturing & $0.959(0.597 \sim 1.54)$ \\
Electricity Supply & $1.285(0.554 \sim 2.98)$ \\
Water Supply & $0.815(0.34 \sim 1.955)$ \\
Construction & $0.932(0.568 \sim 1.528)$ \\
Wholesale & $1.062(0.647 \sim 1.745)$ \\
Transportation & $1.065(0.644 \sim 1.763)$ \\
Food Service & $1.248(0.652 \sim 2.389)$ \\
Information & $1.225(0.58 \sim 2.586)$ \\
Financial Activities & $1.05(0.554 \sim 1.99)$ \\
Real Estate & $1.128(0.503 \sim 2.534)$ \\
Technical Activities & $0.944(0.473 \sim 1.883)$ \\
Support Service & $1.009(0.527 \sim 1.931)$ \\
Public Administration & $0.957(0.447 \sim 2.051)$ \\
Education & $0.971(0.469 \sim 2.01)$ \\
Human Health & $1.153(0.607 \sim 2.19)$ \\
Other Service & $1.196(0.667 \sim 2.147)$ \\
Company Size & \\
Shut Down & $0.856(0.671 \sim 1.092)$ \\
Small & $0.793(0.598 \sim 1.051)$ \\
Medium & $0.92(0.771 \sim 1.099)$ \\
Pathological Stage & \\
Stage 0 \& I & $1.617(1.237 \sim 2.114)$ \\
Stage II & $1.473(1.089 \sim 1.993)$ \\
Stage III & $1.281(0.968 \sim 1.696)$
\end{tabular}

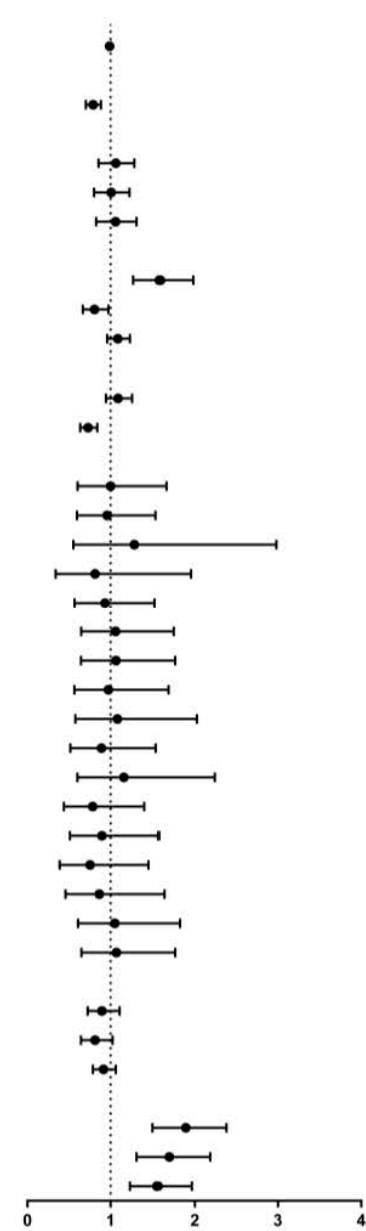

(A) 2-year RTW

\begin{tabular}{ll} 
& \multicolumn{1}{c}{ HR $(95 \% \mathrm{Cl})$} \\
Age & $0.981(0.972 \sim 0.989)$ \\
Gender & \\
Male & $0.772(0.67 \sim 0.889)$ \\
Comorbidity & \\
0 & $1.081(0.841 \sim 1.391)$ \\
1 & $1.019(0.784 \sim 1.325)$ \\
2 & $1.053(0.791 \sim 1.4)$ \\
Treatment & \\
Operation & $2.07(1.496-2.865)$ \\
Radiotherapy & $0.647(0.491-0.853)$ \\
Chemotherapy & $0.976(0.834 \sim 1.144)$ \\
Income Range & \\
S960-S1273 & $0.988(0.83 \sim 1.176)$ \\
>S1273 & $0.573(0.48-0.684)$ \\
Industrial Classification & \\
Agriculture & $1.286(0.66-2.504)$ \\
Manufacturing & $1.212(0.644 \sim 2.282)$ \\
Electricity Supply & $1.388(0.431 \sim 4.469)$ \\
Water Supply & $1.016(0.347 \sim 2.978)$ \\
Construction & $1.336(0.695 \sim 2.565)$ \\
Wholesale & $1.1(0.567 \sim 2.133)$ \\
Transportation & $1.088(0.553 \sim 2.14)$ \\
Food Service & $1.143(0.558-2.343)$ \\
Information & $1.095(0.484 \sim 2.476)$ \\
Financial Activities & $1.136(0.558-2.312)$ \\
Real Estate & $0.66(0.239-1.823)$ \\
Technical Activities & $0.941(0.446 \sim 1.986)$ \\
Support Service & $1.207(0.587 \sim 2.481)$ \\
Public Administration & $1.25(0.558 \sim 2.803)$ \\
Education & $0.992(0.437 \sim 2.25)$ \\
Human Health & $1.634(0.812 \sim 3.287)$ \\
Other Service & $1.413(0.732 \sim 2.727)$ \\
Company Size & \\
Shut Down & $0.848(0.646 \sim 1.113)$ \\
Small & $0.927(0.706 \sim 1.216)$ \\
Medium & $1.02(0.852 \sim 1.222)$ \\
Pathological Stage & \\
Stage 0 \& I & $2.968(2.142 \sim 4.112)$ \\
Stage II & $2.48(1.742 \sim 3.532)$ \\
Stage III & $1.627(1.156-2.289)$ \\
& \\
\hline
\end{tabular}

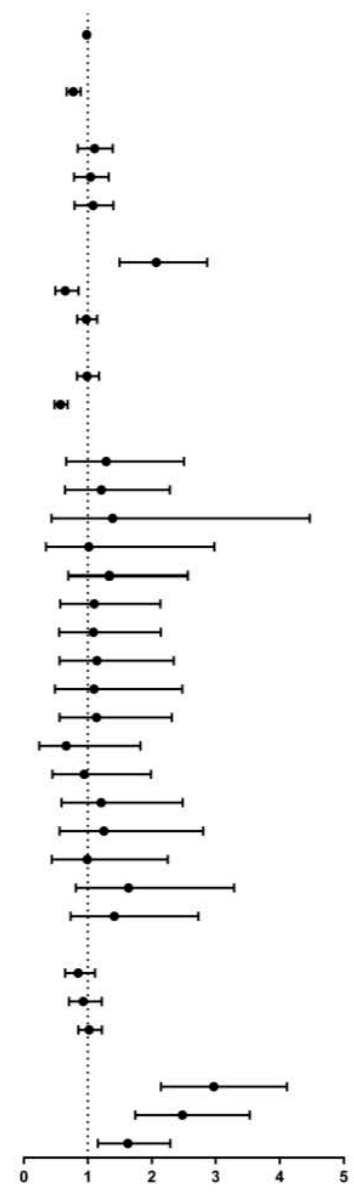

(B) 5-year RTW

Figure 3. Forest tree plot showing the HR obtained by multivariate Cox proportional hazards model of return to work for lung cancer survivors in (A) 2-year RTW and (B) 5-year RTW.

\subsection{Multivariate Analysis of RTW and All-Cause Mortality in Cox Proportional Hazards Models}

After using Cox proportional hazards models to adjust the confounding variables, the association of all-cause mortality between lung cancer survivors who had RTW and those who had not is shown in Table 2. An inverse relationship between all-cause mortality and RTW among lung cancer patients was observed in both the unadjusted and fully adjusted model $(p<0.001 ; p<0.001)$.

Table 2. Uni- and multivariate analysis of RTW and all-cause mortality in Cox proportional hazards models.

\begin{tabular}{ccccc}
\hline & $\begin{array}{c}\text { Unadjusted All-Cause } \\
\text { Mortality }\end{array}$ & $p$ & $\begin{array}{c}\text { Adjusted All-Cause } \\
\text { Mortality }\end{array}$ & $p$ \\
\hline RTW & $0.508(0.447-0.578)$ & $<0.0001$ & $0.508(0.441-0.586)$ & $<0.0001$ \\
\hline
\end{tabular}




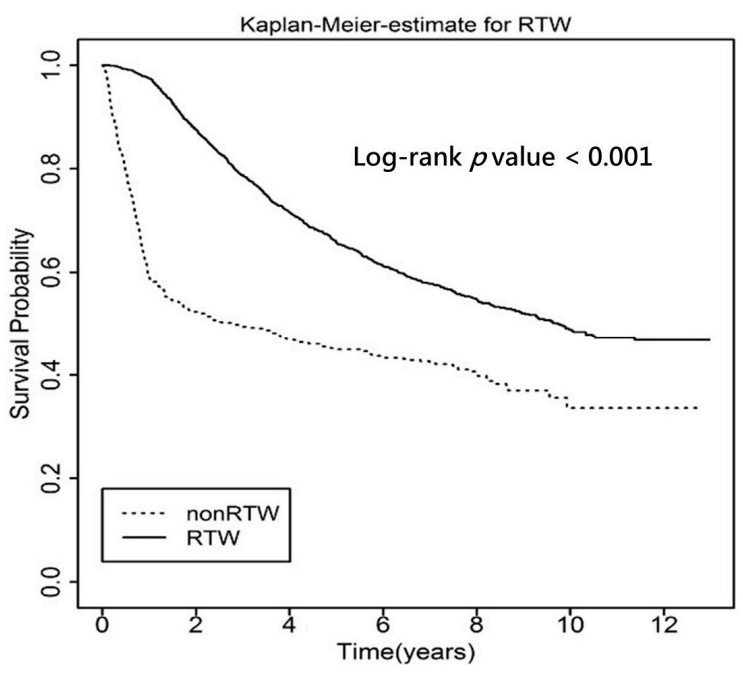

(A) All stages

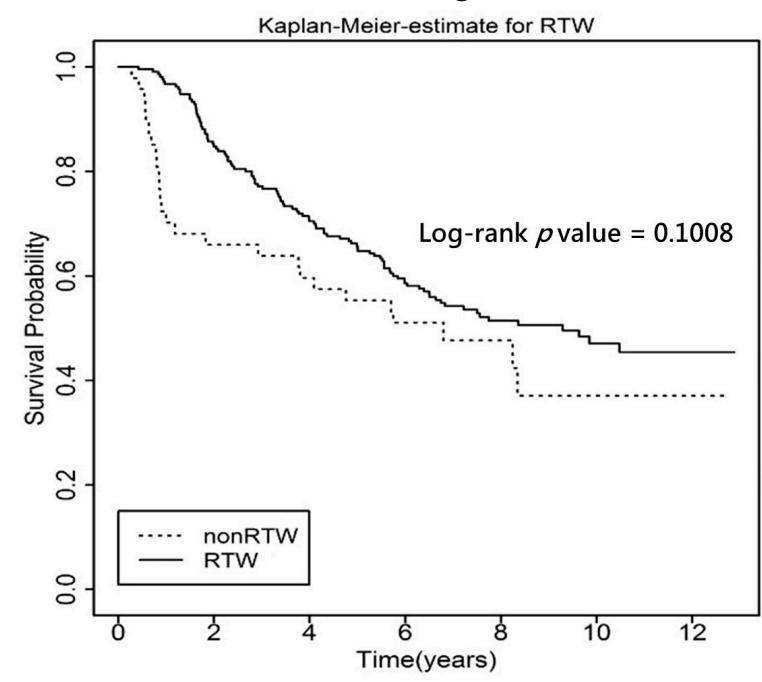

(C) Stage 2

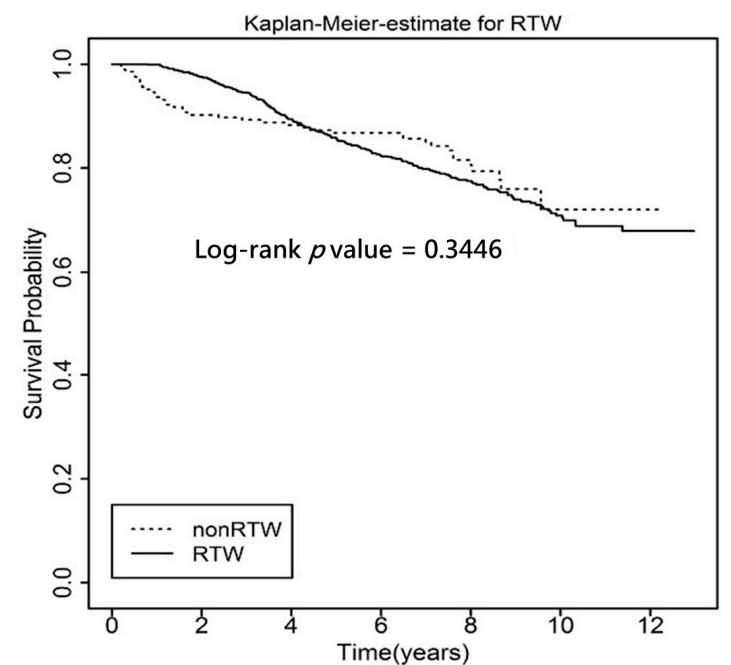

(B) Stages 0 \& 1

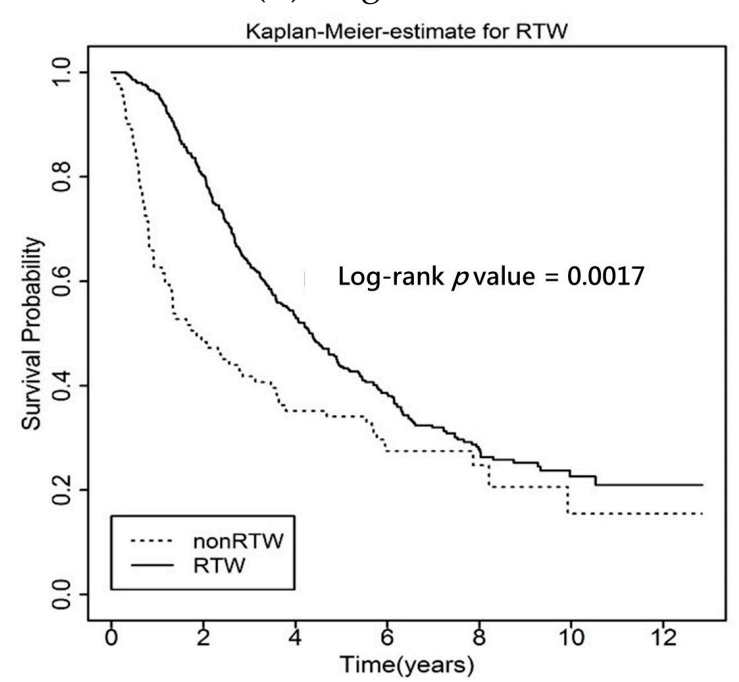

(D) Stage 3

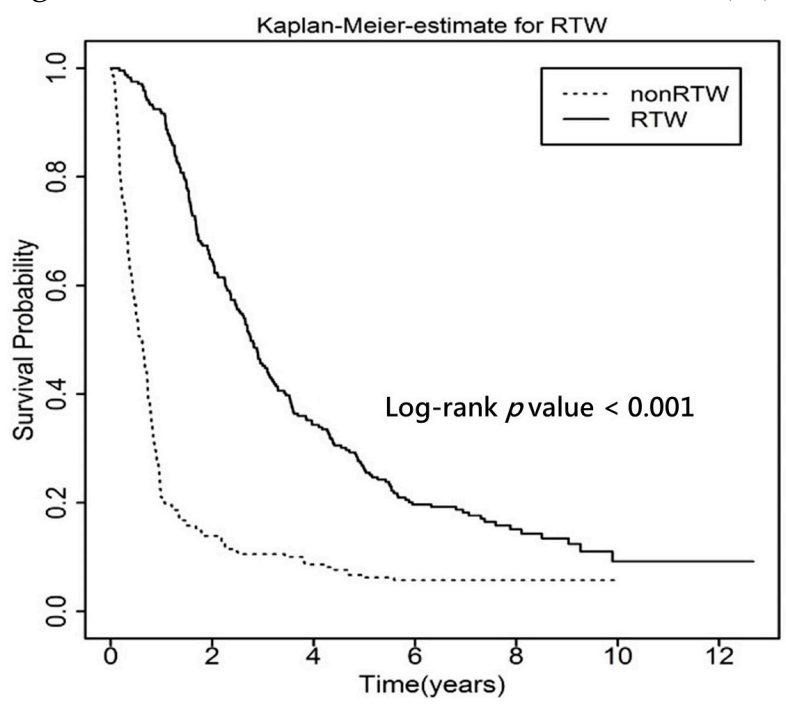

(E) Stage 4

Figure 4. Kaplan-Meier (KM) curves showed survival probability of RTW for (A) all, (B) stages 0 and 1 and (C-E) stages 2-4 lung cancer survivors. 


\section{Discussion}

Our study investigated the independent factors associated with RTW and examined the correlation between all-cause mortality and RTW among lung cancer patients in Taiwan. We found that employees with stages 0, I and II cancer had a higher likelihood of RTW, while factors correlated with a reduced likelihood of RTW were higher income and receiving radiotherapy. Lung cancer survivors who had RTW had lower all-cause mortality rates than those who had not. Moreover, through the Kaplan-Meier curve, the RTW group had better survival rates than the non-RTW group.

There have been many studies examining the association between RTW and cancer survivorship [23]. In a systemic review, Mehnert reported that $40 \%$ of patients had returned to work or had continued to work after 6 months of treatment, $62 \%$ by 12 months and $89 \%$ by 24 months [24]. However, the RTW rate of cancer patients was widely different depending on cancer type. A prospective study demonstrated that patients with breast cancer or skin cancer had a higher RTW rate. On the contrary, patients with lung cancer or head and neck cancer had a lower RTW rate [25]. Another study showed patients with skin or stomach cancer had higher employment rates compared to patients with lung or central nervous system cancer [26]. Earle and his colleagues reported only $21 \%$ of lung cancer survivors remained employed in the 15 months after their cancer diagnosis [27]. A recent cross-sectional study from Germany revealed a 33\% employment rate within 1 year after being diagnosed with lung cancer [28]. Our study found a $41 \%$ employment rate in the fifth year of the follow-up period. The possible reasons for the relatively low RTW rate of lung cancer survivors have been addressed. A review article on the employment-related factors of cancer survivors suggested that the poor 5-year survival rates of lung cancer patients might cause the low likelihood of RTW [29]. Polanski et al. stated that lung cancer survivors had a lower quality of life compared to other cancer survivors [10].

Sociodemographic factors including age, education and income were examined to be associated with RTW [26]. A prospective study in the US indicated that a lower educational level and income were associated with unemployment [27]. Kim and his colleagues found that a low employment rate was correlated with older age and lower household income among lung cancer survivors [18]. However, our study revealed that a higher monthly income was correlated with a lower likelihood of RTW, which is inconsistent with previous studies. There are several explanations for these conflicting findings. The Taiwanese National Health Insurance system has provided comprehensive coverage, including the medical expense of cancer treatment [30]. The coverage rate of the Taiwanese National Health Insurance is nearly $99.9 \%$, and around $93 \%$ of medical care institutions in Taiwan are contracted with the National Health Insurance system. Taken together, cancer patients in Taiwan face less financial stress on treatment costs. From an economic perspective, the higher monthly income group might have better financial reserves that allow them to take long-term sick leave.

In the present study, we found that lung cancer survivors who had RTW had higher survival rates and lower risk of all-cause mortality. An American review stated that RTW could help to improve recovery in many aspects, such as social, psychological and physical functioning [31]. Schmidt et al. discovered that participants who RTW have a better quality of life and cognitive performance than those who did not RTW [32]. A cross-sectional study from a single cancer center demonstrated that cancer survivors who remained in their jobs had fewer mental illnesses compared with those were out of work [33]. According to these findings, re-employment in cancer patients might indicate the recovery of physical function and improvement of cancer survival. Our results are in line with this inference.

There are several limitations in our study. First, there was a lack of information about other sociodemographic factors and psychosocial work-related factors, which may be possible confounding factors affecting the RTW. Second, we only recruited Taiwanese participants, which might limit the generalizability of our findings to different racial populations. Third, we did not take into account the side effects of treatment, such as fatigue, which was the most common work-related problem in lung cancer patients. 


\section{Conclusions}

Our study showed RTW was correlated with a lower risk of all-cause mortality and better lung cancer survival. The findings might be explained by a stable income and better performance status accompanied by RTW. Our results demonstrated the impact of RTW and independent confounding factors in lung cancer survivorship. Accessing the side effects of treatment, quality of life, work accommodation and work discrimination may be considered in future studies.

Supplementary Materials: The following are available online at https:/ /www.mdpi.com/article/10 .3390/ijerph19010309/s1, Table S1: The ICD-9-CM codes for clinical comorbidities.

Author Contributions: Z.-Y.Y. contributed to the design of the study, was responsible for dataanalysis decisions, was responsible for the management and retrieval of data, decided on datacollection methods and initial data analysis and interpretation, contributed to initial data analysis and interpretation, and drafted the initial article. C.-H.L. and C.-L.H. decided on the data-collection methods and initial data analysis and interpretation. C.-C.W. conceptualized and designed the study, contributed to the design of the study, supervised all aspects of the study, was responsible for data-analysis decisions, decided on data-collection methods and initial data analysis and interpretation, was responsible for the management and retrieval of data, contributed to initial data analysis and interpretation, drafted the initial article, critically reviewed and revised the article, and approved the final version for submission. All authors meet the International Committee of Medical Journal Editors criteria for authorship. All authors have read and agreed to the published version of the manuscript.

Funding: This study was supported by the Institute of Labor, Occupational Safety, and Health (ILOSH) and the Ministry of Labor (ILOSH107-M301) in Taiwan.

Institutional Review Board Statement: The study was conducted according to the guidelines of the Declaration of Helsinki and approved by the Institutional Review Board of Tri-Service General Hospital (TSGH) (IRB No. 1-107-05-129).

Informed Consent Statement: Subject informed consent was waived in this study because our data were collected from the database of the Taiwan Cancer Registry (TCR), Labor Insurance Database (LID) and National Health Insurance Research Database (NHIRD). Those databases were provided under de-identification status. We can only link the data by a unique encryption identity number. All of the procedures were approved by the Institutional Review Board (IRB) of Tri-Service General Hospital, Taiwan (IRB No. 1-107-05-129).

Data Availability Statement: The data underlying this study are from the Labor Insurance Database (LID) and National Health Insurance Research Database (NHIRD). The LID and NHIRD is not free to public access, and therefore, interested researchers can obtain the data through formal application to the Health and Welfare Data Science Center, Ministry of Health and Welfare, Taiwan. (https: / / dep.mohw.gov.tw/DOS/np-2497-113.html). Last accessed date: 29 June 2020.

Acknowledgments: We gratefully acknowledge the contribution of the late Saou-Hsing Liou and Ya-Yuan Hsu to this paper.

Conflicts of Interest: The authors declared that they had no competing interests.

\section{References}

1. Sung, H.; Ferlay, J.; Siegel, R.L.; Laversanne, M.; Soerjomataram, I.; Jemal, A.; Bray, F. Global Cancer Statistics 2020: GLOBOCAN Estimates of Incidence and Mortality Worldwide for 36 Cancers in 185 Countries. CA Cancer J. Clin. 2021, 71, 209-249. [CrossRef] [PubMed]

2. Siegel, R.L.; Miller, K.D.; Fuchs, H.E.; Jemal, A. Cancer Statistics, 2021. CA Cancer J. Clin. 2021, 71, 7-33. [CrossRef] [PubMed]

3. Malhotra, J.; Malvezzi, M.; Negri, E.; La Vecchia, C.; Boffetta, P. Risk factors for lung cancer worldwide. Eur. Respir. J. 2016, 48, 889-902. [CrossRef] [PubMed]

4. Torre, L.A.; Siegel, R.L.; Jemal, A. Lung Cancer Statistics. Adv. Exp. Med. Biol. 2016, 893, 1-19. [CrossRef]

5. Latimer, K.M.; Mott, T.F. Lung cancer: Diagnosis, treatment principles, and screening. Am. Fam. Physician 2015, 91, 250-256.

6. Chirieac, L.R.; Dacic, S. Targeted Therapies in Lung Cancer. Surg. Pathol. Clin. 2010, 3, 71-82. [CrossRef]

7. Corrales, L.; Scilla, K.; Caglevic, C.; Miller, K.; Oliveira, J.; Rolfo, C. Immunotherapy in Lung Cancer: A New Age in Cancer Treatment. Adv. Exp. Med. Biol. 2018, 995, 65-95. [CrossRef] 
8. Jonas, D.E.; Reuland, D.S.; Reddy, S.M.; Nagle, M.; Clark, S.D.; Weber, R.P.; Enyioha, C.; Malo, T.L.; Brenner, A.T.; Armstrong, C.; et al. Screening for Lung Cancer with Low-Dose Computed Tomography: Updated Evidence Report and Systematic Review for the US Preventive Services Task Force. JAMA 2021, 325, 971-987. [CrossRef]

9. Howlader, N.; Forjaz, G.; Mooradian, M.J.; Meza, R.; Kong, C.Y.; Cronin, K.A.; Mariotto, A.B.; Lowy, D.R.; Feuer, E.J. The Effect of Advances in Lung-Cancer Treatment on Population Mortality. N. Engl. J. Med. 2020, 383, 640-649. [CrossRef]

10. Polanski, J.; Jankowska-Polanska, B.; Rosinczuk, J.; Chabowski, M.; Szymanska-Chabowska, A. Quality of life of patients with lung cancer. Onco. Targets Ther. 2016, 9, 1023-1028. [CrossRef]

11. Vijayvergia, N.; Shah, P.C.; Denlinger, C.S. Survivorship in Non-Small Cell Lung Cancer: Challenges Faced and Steps Forward. J. Natl. Compr. Cancer Netw. 2015, 13, 1151-1161. [CrossRef] [PubMed]

12. Hechtner, M.; Eichler, M.; Wehler, B.; Buhl, R.; Sebastian, M.; Stratmann, J.; Schmidberger, H.; Gohrbandt, B.; Peuser, J.; Kortsik, C.; et al. Quality of Life in NSCLC Survivors-A Multicenter Cross-Sectional Study. J. Thorac. Oncol. 2019, 14, $420-435$. [CrossRef] [PubMed]

13. Khue, P.M.; Thom, V.T.; Minh, D.Q.; Quang, L.M.; Hoa, N.L. Depression and Anxiety as Key Factors Associated with Quality of Life Among Lung Cancer Patients in Hai Phong, Vietnam. Front. Psychiatry 2019, 10. [CrossRef] [PubMed]

14. Arrieta, O.; Angulo, L.P.; Nunez-Valencia, C.; Dorantes-Gallareta, Y.; Macedo, E.O.; Martinez-Lopez, D.; Alvarado, S.; CoronaCruz, J.F.; Onate-Ocana, L.F. Association of depression and anxiety on quality of life, treatment adherence, and prognosis in patients with advanced non-small cell lung cancer. Ann. Surg. Oncol. 2013, 20, 1941-1948. [CrossRef]

15. Nekhlyudov, L.; Walker, R.; Ziebell, R.; Rabin, B.; Nutt, S.; Chubak, J. Cancer survivors' experiences with insurance, finances, and employment: Results from a multisite study. J. Cancer Surviv. 2016, 10, 1104-1111. [CrossRef]

16. Carrera, P.M.; Kantarjian, H.M.; Blinder, V.S. The financial burden and distress of patients with cancer: Understanding and stepping-up action on the financial toxicity of cancer treatment. CA Cancer J. Clin. 2018, 68, 153-165. [CrossRef]

17. Zhang, X.; Liu, S.; Liu, Y.; Du, J.; Fu, W.; Zhao, X.; Huang, W.; Zhao, X.; Liu, G.; Mao, Z.; et al. Economic Burden for Lung Cancer Survivors in Urban China. Int. J. Environ. Res. Public Health 2017, 14, 308. [CrossRef]

18. Kim, Y.A.; Yun, Y.H.; Chang, Y.J.; Lee, J.; Kim, M.S.; Lee, H.S.; Zo, J.I.; Kim, J.; Choi, Y.S.; Shim, Y.M.; et al. Employment status and work-related difficulties in lung cancer survivors compared with the general population. Ann. Surg. 2014, 259, 569-575. [CrossRef]

19. Torp, S.; Nielsen, R.A.; Fosså, S.D.; Gudbergsson, S.B.; Dahl, A.A. Change in employment status of 5-year cancer survivors. Eur. J. Public Health 2012, 23, 116-122. [CrossRef]

20. Sjövall, K.; Attner, B.; Englund, M.; Lithman, T.; Noreen, D.; Gunnars, B.; Thomé, B.; Olsson, H.; Petersson, I.F. Sickness absence among cancer patients in the pre-diagnostic and the post-diagnostic phases of five common forms of cancer. Support. Care Cancer 2012, 20, 741-747. [CrossRef]

21. Bradburn, M.J.; Clark, T.G.; Love, S.B.; Altman, D.G. Survival analysis part II: Multivariate data analysis-an introduction to concepts and methods. Br. J. Cancer 2003, 89, 431-436. [CrossRef]

22. Goel, M.K.; Khanna, P.; Kishore, J. Understanding survival analysis: Kaplan-Meier estimate. Int. J. Ayurveda Res. 2010, 1, 274-278. [CrossRef]

23. van Muijen, P.; Weevers, N.L.; Snels, I.A.; Duijts, S.F.; Bruinvels, D.J.; Schellart, A.J.; van der Beek, A.J. Predictors of return to work and employment in cancer survivors: A systematic review. Eur. J. Cancer Care 2013, 22, 144-160. [CrossRef]

24. Mehnert, A. Employment and work-related issues in cancer survivors. Crit. Rev. Oncol. Hematol. 2011, 77, 109-130. [CrossRef]

25. Mehnert, A.; Koch, U. Predictors of employment among cancer survivors after medical rehabilitation-A prospective study. Scand. J. Work Environ. Health 2013, 39, 76-87. [CrossRef]

26. Kiasuwa Mbengi, R.; Otter, R.; Mortelmans, K.; Arbyn, M.; Van Oyen, H.; Bouland, C.; de Brouwer, C. Barriers and opportunities for return-to-work of cancer survivors: Time for action-Rapid review and expert consultation. Syst. Rev. 2016, 5, 35. [CrossRef]

27. Earle, C.C.; Chretien, Y.; Morris, C.; Ayanian, J.Z.; Keating, N.L.; Polgreen, L.A.; Wallace, R.; Ganz, P.A.; Weeks, J.C. Employment among survivors of lung cancer and colorectal cancer. J. Clin. Oncol. 2010, 28, 1700-1705. [CrossRef] [PubMed]

28. Rashid, H.; Eichler, M.; Hechtner, M.; Gianicolo, E.; Wehler, B.; Buhl, R.; Schmidberger, H.; Stratmann, J.A.; Gohrbandt, B.; Kortsik, C.; et al. Returning to work in lung cancer survivors-A multi-center cross-sectional study in Germany. Support. Care Cancer 2021, 29, 3753-3765. [CrossRef]

29. Taskila, T.; Lindbohm, M.L. Factors affecting cancer survivors' employment and work ability. Acta. Oncol. 2007, 46, 446-451. [CrossRef] [PubMed]

30. Hung, M.-C.; Lai, W.-W.; Chen, H.H.W.; Lee, J.-C.; Lin, Y.-J.; Hsiao, J.-R.; Cheng, Y.-M.; Shan, Y.-S.; Su, W.-C.; Wang, J.-D. Cost effectiveness of cancer treatment in Taiwan. J. Formos. Med. Assoc. 2016, 115, 609-618. [CrossRef] [PubMed]

31. Feuerstein, M.; Todd, B.L.; Moskowitz, M.C.; Bruns, G.L.; Stoler, M.R.; Nassif, T.; Yu, X. Work in cancer survivors: A model for practice and research. J. Cancer Surviv. 2010, 4, 415-437. [CrossRef]

32. Schmidt, M.E.; Scherer, S.; Wiskemann, J.; Steindorf, K. Return to work after breast cancer: The role of treatment-related side effects and potential impact on quality of life. Eur. J. Cancer Care 2019, 28, e13051. [CrossRef] [PubMed]

33. Kuroki, L.M.; Morris, D.H.; Greenwade, M.; Landon, M.; Hagemann, A.R.; Thaker, P.H.; Massad, L.S.; McCourt, C.K.; Fuh, K.C.; Powell, M.A.; et al. Impact of employment and insurance status on distress in gynecologic oncology patients. Gynecol. Oncol. 2021, 161, 477-482. [CrossRef] [PubMed] 